Article

\title{
Isolation and Characterization of New Temperature Tolerant Microalgal Strains for Biomass Production
}

\author{
Franziska Bleeke ${ }^{1,2}$, Vincent M. Rwehumbiza ${ }^{2}$, Dominik Winckelmann ${ }^{2}$ and Gerd Klöck ${ }^{2, *}$ \\ 1 School of Engineering and Science, Jacobs University, 28759 Bremen, Germany; \\ E-Mail: franziska.bleeke@hs-bremen.de \\ 2 Institute of Environmental Biology and Biotechnology, University of Applied Sciences Bremen, \\ 28199 Bremen, Germany; E-Mails: v.rwehumbiza@gmail.com (V.M.R.); \\ dominik.winckelmann@hs-bremen.de (D.W.) \\ * Author to whom correspondence should be addressed; E-Mail: gerd.kloeck@hs-bremen.de; \\ Tel.: +49-421-5905-4266, Fax: +49-421-5905-4245.
}

External Editor: Paul L. Chen

Received: 7 August 2014; in revised form: 17 November 2014 / Accepted: 18 November 2014 / Published: 25 November 2014

\begin{abstract}
Microalgae exhibit great potential for biomass production. Although microalgae display an enormous biodiversity, surprisingly only 15 species are used for large scale production processes worldwide. The implementation of new production strains with good process-oriented properties, especially fast growth rate and heat resistance, could improve production efficiency and reduce costs. In this study 130 environmental samples collected in Germany, Spain, Italy and Portugal were investigated for fast growing thermotolerant photosynthetic species. Isolates were characterized and identified on a molecular level. In total 21 of the isolated freshwater strains were able to grow at $40{ }^{\circ} \mathrm{C}$. Additionally, 13 of those 21 strains are able to grow at $45{ }^{\circ} \mathrm{C}$. The highest growth rate at room temperature was 1.16 per day (isolate T306A), compared to 0.053 per day at $45{ }^{\circ} \mathrm{C}$ (isolate $\mathrm{Sp} 13$ ). In three thermotolerant strains pigment production was induced. Molecular identification by $18 \mathrm{~S}$ rDNA sequencing revealed that the isolates were all chlorophytes belonging to four different families.
\end{abstract}

Keywords: screening; high temperature tolerance; biomass production; freshwater microalgae; pigments 


\section{Introduction}

Microalgae are microscopically small photosynthetically active eukaryotic organisms with an increasing importance in the biotechnology sector. Compared to higher plants they have several advantages, such as faster growth, the ability to be grown on non-arable land and the capacity to accumulate valuable products such as lipids or pigments [1,2].

There are between 200,000 and several million microalgal species [3,4]. Even though microalgae display an enormous biotechnological potential due to their biodiversity and versatility, the industry is currently using only about 15 species for large scale production [5]. Due to the increasing demand for microalgal biomass, a process-oriented strain selection is essential in order to make large scale production economical. Process-oriented strain selection supports the use of either indigenous strains from the respective production site, or strains adapted to stress, which due to fast growth rates are able to outcompete predators or weed algae. Besides light exposure and nutrient availability, the temperature influences growth efficiency significantly. Due to high and favorable illumination the summer months usually lead to high biomass productivities [6]. The optimal growth temperature for common laboratory strains of microalgae varies among different species, but is usually stated to be between 20 and $30{ }^{\circ} \mathrm{C}[6-11]$.

Higher temperature conditions in greenhouses or outdoor cultivation settings during summer months may negatively affect growth of many microalgal species $[6,8,12]$. In greenhouses temperatures can reach up to $55{ }^{\circ} \mathrm{C}$, resulting in maximum culture temperatures exceeding $35{ }^{\circ} \mathrm{C}$ [13]. For outdoor cultivation similar temperatures surpassing $35^{\circ} \mathrm{C}$ and even $40{ }^{\circ} \mathrm{C}$ were reported [14-18]. Whereas temperatures below the optimum lead to a retained biomass production, temperatures above the optimum results in a steep decrease in productivity and possibly the total loss of the culture. The degradation and inactivation of enzymes involved in the photosynthetic process caused by heat stress results in the inhibition of growth or even programmed cell death $[1,12,19]$. Construction of temperature controlled environments for cultivation of microalgae would be ideal, but has been proven to not be sustainable due to high initial investment and operation costs. Therefore, acquiring microalgae strains with the ability to grow and propagate in these severe heat conditions, especially during summer temperatures, is of utmost importance.

In the present study a simple screening protocol for environmental algal samples was developed. Within this screening the main focus was put on thermotolerant freshwater species with a high growth rate. 130 samples were collected in Germany, Italy, Spain, and Portugal and later analyzed. After an initial temperature tolerance test, pure cultures were obtained and characterized.

\section{Results and Discussion}

\subsection{Sampling and Enrichment}

One hundred and thirty samples from Germany, Italy, Spain and Portugal were collected and cultivated in test tubes containing Wuxal liquid medium (WM) [20]. The incubation resulted in algal growth in about $50 \%$ of the test tubes, leaving 66 samples for the screening procedure. Figure 1 shows a variety of cell types and shapes that could be observed in the test tubes using a Zeiss Axiostar Plus 
light microscope (Carl Zeiss, Oberkochen, Germany) investigated in Hellfeld mode at 40-fold magnification. The images were taken by a FinePix E550 digital camera (Fujifilm, Tokyo, Japan).

Figure 1. Morphological diversity of the mixed cultures in the test tubes. (a) mixed culture of pennate gold-brown single cells; (b) intense green filamentous microalgae; (c) mixed culture of coccoid and elongated single cells; and (d) flagellated protists with red eyespots visible.

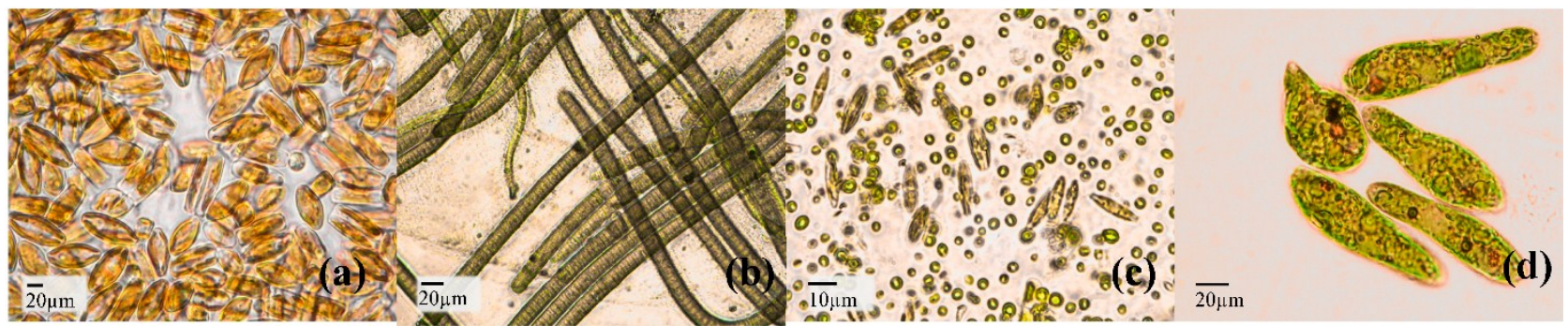

\subsection{Temperature Tolerance and Growth Kinetics}

After incubation at $25{ }^{\circ} \mathrm{C}$ for 14 days, 7 (of 66) test tubes showed a decrease in coloration leaving 59 test tubes for further screening. In the following step the cultures were transferred to conical flasks (volume $100 \mathrm{~mL}$ ) and exposed to $35{ }^{\circ} \mathrm{C}$ for seven days. This step left 40 samples for further investigations. After this initial enrichment of temperature tolerant samples, unialgal isolates were obtained by microbiological methods. These isolates were subjected to further temperature tolerance tests. When the growth temperature was further increased, 21 out of those 40 isolates were able to grow at $40{ }^{\circ} \mathrm{C}$ (Table 1), 13 of them were even growing at $45{ }^{\circ} \mathrm{C}$. None of the isolates grew at $47{ }^{\circ} \mathrm{C}$ (Table 1, Figure 2).

Figure 2. Temperature tolerance test of purified isolates. Thirteen algae strains tolerated incubation at $45{ }^{\circ} \mathrm{C}$. The highest growth could be observed for isolates Sp13, Sp14, I4, I5 and CS after a $48 \mathrm{~h}$ lag phase. A further temperature increase to $47^{\circ} \mathrm{C}$ led to a decline in optical density after $48 \mathrm{~h}$. Data points are the mean value of three replicates. Error bars represent standard deviation.

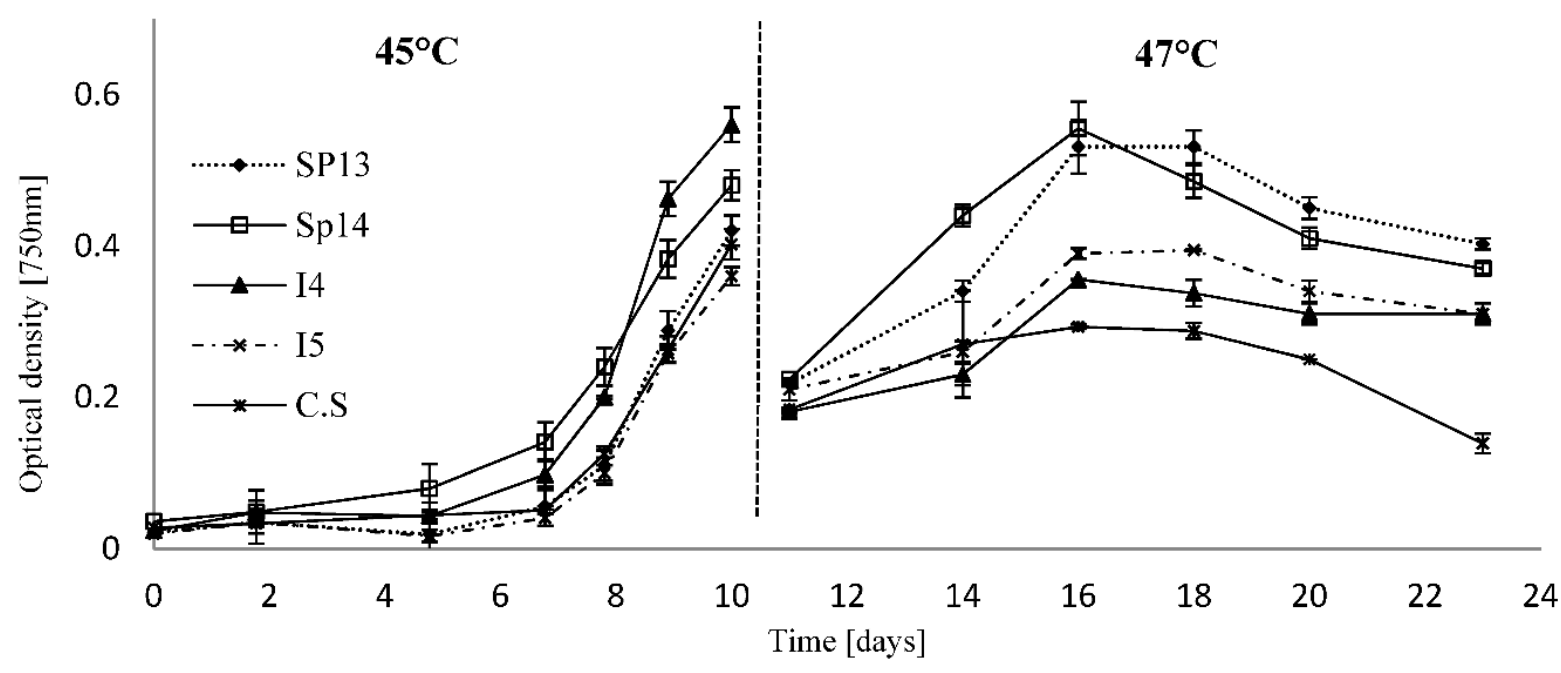


Table 1. Growth rates and the maximal temperature tolerated for biomass production of 22 unialgal isolates obtained after initial enrichment.

\begin{tabular}{ccc}
\hline Isolate & $\boldsymbol{\mu ~ d a y}^{-\mathbf{1}}$ & Maximal Temperature $\left[{ }^{\circ} \mathbf{C}\right]$ \\
\hline T306A & 1.163 & 45 \\
Sp1 & 1.101 & 40 \\
CS & 0.943 & 45 \\
T301 & 0.890 & 45 \\
I5 & 0.832 & 45 \\
Sp12 & 0.827 & 45 \\
Sp13 & 0.766 & 45 \\
Sp14 & 0.683 & 45 \\
T308 & 0.667 & 40 \\
Sp9 & 0.646 & 45 \\
GDK & 0.625 & 40 \\
T302 & 0.585 & 45 \\
T306B & 0.564 & 45 \\
T307 & 0.525 & 40 \\
I4 & 0.469 & 45 \\
Sp6 & 0.455 & 40 \\
R6 & 0.423 & 45 \\
R4 & 0.382 & 40 \\
Ssp & 0.371 & 40 \\
R3 & 0.328 & 45 \\
I1 & 0.144 & 35 \\
I3 & 0.105 & 40 \\
\hline
\end{tabular}

During incubation at $45^{\circ} \mathrm{C}$ all isolates experienced a lag phase in the first $48 \mathrm{~h}$. This lag phase was extended to $48 \mathrm{~h}$ for isolate I4, I5 and Sp13 and to $120 \mathrm{~h}$ for isolate CS. For most samples, the optical density measured at $750 \mathrm{~nm}$ wavelength started to rise after $48 \mathrm{~h}$. The highest values were attained by I4 and Sp14 after 10 days of incubation. Determination of the cell number revealed the same trend (data not shown). Although isolate Sp13 showed the highest growth rate (Table 1), the final OD 750 value of 0.42 was lower compared to isolates I4 and Sp14 of 0.56 and 0.48 , respectively. Five days of incubation showed an increase in cell number for all tested isolates. Comparing the growth rates of the isolates grown at room temperature and $45^{\circ} \mathrm{C}$, the effects of thermal induced stress were evident. The growth rates for CS, I4, I5, Sp13 and Sp14 at $45{ }^{\circ} \mathrm{C}$ were approximately $50 \%$ of the values determined at room temperature (Table 2). It was also noted that the samples cultivated at room temperature were light green while the ones grown at $45^{\circ} \mathrm{C}$ were dark green.

Table 2. Comparison of growth rates at room temperature $\left(22 \pm 1^{\circ} \mathrm{C}\right)$ and $45^{\circ} \mathrm{C}$.

\begin{tabular}{ccc}
\hline Isolate & $\boldsymbol{\mu} \mathbf{d a y}^{-\mathbf{1}}\left(\mathbf{2 2} \pm \mathbf{1}^{\circ} \mathbf{C}\right)$ & $\boldsymbol{\mu} \mathbf{d a y}^{-\mathbf{1}}\left(\mathbf{4 5}{ }^{\circ} \mathbf{C}\right)$ \\
\hline Sp13 & 0.766 & 0.53 \\
CS & 0.943 & 0.42 \\
I4 & 0.469 & 0.4 \\
I5 & 0.832 & 0.39 \\
Sp14 & 0.683 & 0.37 \\
\hline
\end{tabular}


Organisms inhabiting places in warmer regions are usually exposed to a wide variety of temperature conditions. Their capability to adapt to rapid changes in environmental stresses, such as temperature shifts, is an essential requirement for survival. In this study, the analyzed microalgae species responded to thermal stress exposure in various ways. The results of the temperature sensitivity tests revealed that 21 isolates out of 130 samples were able to grow at temperatures of $40{ }^{\circ} \mathrm{C}$ or even higher. The aim of this study was to obtain a greater biodiversity of thermotolerant strains and surprisingly 13 of the identified strains were genetically identified to belong to the family Chlorellaceae (Figure S1). It is well known that some Chlorella species tolerate a broad temperature range and have been used as model organisms for physiological studies on broad temperature tolerance of microorganisms [6,8,19,21]. This study confirms the reported ability of Chlorella strains to adapt and grow at high temperatures. Species belonging to genus Chlorella seems to be suitable for cultivation at high temperatures in outdoor settings or greenhouses.

\subsection{Establishment of Unialgal Cultures}

Twenty three monoalgal cultures were attained by using the thirteen-streak-method (Figure 3) [22]. The morphological features of the isolates were analyzed using a Zeiss Axiostar Plus light microscope (Figure 4). The samples were investigated in Hellfeld mode at 40 -fold magnification. The images were taken using a Fujifilm FinePix E550 digital camera with macro function. Bacterial contamination occurred frequently during isolation making it necessary to repeat the procedure several times on agar media supplemented with antibiotics. No cyanobacteria were isolated as a result and fast growing colonies were selected and purified. This step makes it possible to adapt the screening procedure to other desired algae properties or products such as pigments.

Figure 3. Establishment of pure cultures. (a) After purifying the environmental samples by using the thirteen-streak-method; (b) monocultures were obtained; (c) and kept in collection.

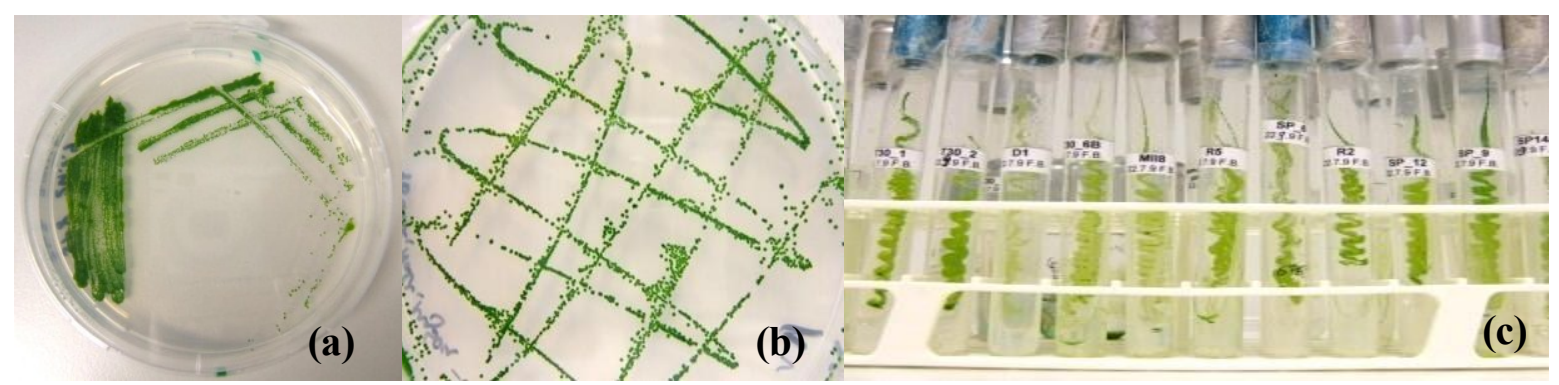

\subsection{Molecular Identification}

This work established the phylogenetic relationships of microalgae strains that could survive and/or grow between 35 and $45^{\circ} \mathrm{C}$ relative to known microalgal genera and species. Twenty two isolates were genetically identified on molecular level via $18 \mathrm{~S}$ rDNA sequencing and could be assigned to four different families (Scenedesmaceae, Chlorellaceae, Chlamydomonadaceae and Chlorococcaceae) and three different orders (Chlorococcales, Chlorellales and Volvocales) (Figure S1: Phylogenetic tree, Table S1: Accesion numbers). 
Figure 4. Microscopic images of isolated species. (a) Sp14 (Chlorellaceae): Spherical cells with large vacuoles; (b) Sp1 (Chlorellaceae): elongated cylindrical cells; (c) T301 (Chlorellaceae): spherical single cells; (d) T309 (Chlorococcaceae): large coccoid cells containing zoospores; (e) R3 (Scenedesmaceae): spherical and ellipsoidal cells; (f) GDK (Scenedesmaceae): single cells and parental cells containing spores; (g) I3 (Scenedesmaceae): two and four cell cenobia with spines visible; (h) I1 (Chlamydomonadaceae): motile green ovoid cells with flagella.

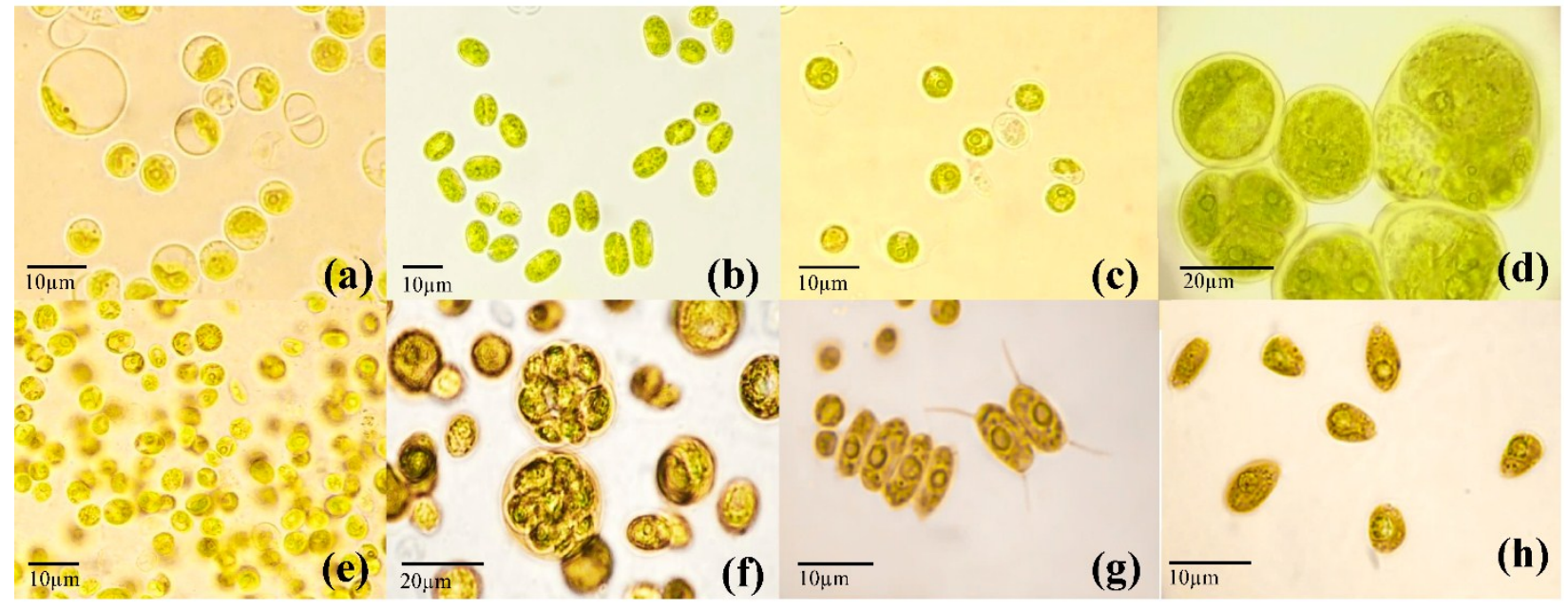

The SSU rDNA (18S rDNA) is usually investigated for relationships between eukaryotic cells as the gene showns a slow evolutionary rate, bears well-conserved as well as rapidly evolving regions and is available in high copy numbers [23,24]. Using for example single gene analysis the small subunit ribosomal DNA (SSU rDNA) gene provides the basic structure for phylogenetic topologies but might be misleading in some aspects. Additional gene sequences could be investigated to improve the resolution of the tree, although the possibility of systematic errors increases with the number of genes and species involved [25].

\section{Experimental Section}

\subsection{Sample Collection and Incubation}

Samples were taken by using commercial cotton buds. After sampling, the cotton buds were wrapped into film to maintain moisture and then sent to the Laboratory of the University of Applied Sciences Bremen. The microalgae were inoculated by gently stirring the cotton buds into test tubes containing Wuxal liquid medium (WM) [20]. Test tubes were kept at $25{ }^{\circ} \mathrm{C}$ for two weeks in a light incubator to allow microalgal growth and any test tubes showing no algal growth after two weeks were removed.

\subsection{Temperature Tolerance Test}

An initial experiment increased the temperature to $35{ }^{\circ} \mathrm{C}$ for seven days. Test tubes showing a decrease in growth (macroscopically evaluated) were removed. In the following temperature increase experiment the mix cultures were transferred into $100 \mathrm{~mL}$ conical flasks and fresh WM was added. The flasks were incubated in a light incubator with a light/dark cycle of 12:12 h and exposed to higher 
temperatures for six hours per day. The cultures were illuminated with $105 \mu \mathrm{mol}$ photons $\mathrm{m}^{-2} \cdot \mathrm{s}^{-1}$. Temperature pattern as well as light intensities during incubation were recorded using HOBO Data Logger (Onset, Linnich, Germany). For each sample a control was incubated at room temperature $\left(22 \pm 1{ }^{\circ} \mathrm{C}\right.$ ). Starting at $40^{\circ} \mathrm{C}$ for seven days, the temperature was then increased daily by $1{ }^{\circ} \mathrm{C}$ increments up to $45^{\circ} \mathrm{C}$ for ten days. Any cultures showing growth at $45^{\circ} \mathrm{C}$ after ten days were exposed to $47^{\circ} \mathrm{C}$ for another twelve days.

\subsection{Establishment of Pure Cultures}

Pure cultures were established by using the thirteen-streak-method [22]. Agar (15 g) was added to the liquid media before autoclaving to prepare solid WM. To inhibit bacterial growth an antibiotic cocktail was added to the agar by mixing penicillin $(1.0 \mathrm{~g})$, streptomycin $(0.5 \mathrm{~g})$ and chloramphenicol $(0.1 \mathrm{~g})$ with deionized water $(16 \mathrm{~mL})$, so that the final concentration of the antibiotic mix in the growth medium was $0.01 \% v / v$. Single colonies were picked and recultured first on solid media and then in liquid media. The microalgae were cultivated at room temperature under sterile conditions in $50 \mathrm{~mL} \mathrm{WM}$ liquid media in $100 \mathrm{~mL}$ conical flasks at $100 \mathrm{rpm}$. Fresh medium was added every 14 days. If no pure culture could be established after five purification cycles (thirteen-streak-method with subsequent plating), the sample was excluded from the screening.

\subsection{Growth Kinetics}

In order to compare the growth of the microalgae, the measured cell count data was standardized by calculating growth rates. Microalgae cultures were grown in batch cultures at an initial cell count of $1 \times 10^{6}-1 \times 10^{7}$ cells $\mathrm{mL}^{-1}$. These cultures were incubated at room temperature for approximately two weeks, until stationary phase was reached. Sampling was performed every two or three days by taking $1 \mathrm{~mL}$ of each culture in triplicate and measuring the optical density at $750 \mathrm{~nm}$ and to determine the cell count using the Thoma counting chamber (Paul Marienfeld GmbH + Co. KG, Lauda-Königshofen, Germany).

\subsection{Molecular Identification}

DNA extraction was performed using the DNeasy Plant Mini Kit (Qiagen GmbH, Hilden, Germany). The 18S rDNA amplification was performed in a T3 thermocycler (Biometra, Göttingen, Germany) with the primer pair EukA and EukB and additional internal primers (Table 3). The amplified products were purified using the MiniElute PCR Purification kit (Qiagen $\mathrm{GmbH}$ ) then sequenced using the BigDye Terminator sequencing kit (Applied Biosystems, Foster City, CA, USA). Residual nucleotides and PCR reagents were washed and removed by DyeEx Spin Kit (Qiagen) and sequencing was performed on an ABI 3100 Avant Sequencer (Applied Biosystems).

Signals generated by the capillary sequencer were investigated using the Sequencing Analysis Software v5.4 (Applied Biosystems). Single sequences were assembled to contigs using DNAStar (Madison, WI, USA) and consensus sequences were calculated. Using the BLAST (Basic Local Alignment Search Tool) algorithm (National Library of Medicine, Bethesda, MD, USA), related sequences were collected from the GenBank and a multiple sequence alignment was carried out using ClustalX (Conway Institute, UCD, Dublin, Ireland). The phylogenetic tree was constructed using 
Mega 4.1 (Center for Evolutionary Functional Genomics, Tempe, AZ, USA) with the neighbor joining clustering method based on the maximum likelihood model with 1000 bootstrap replicates.

Table 3. The oligonucleotide primers used for amplification and sequencing of $18 \mathrm{~S}$ rDNA of selected microalgae strains.

\begin{tabular}{ccc}
\hline Primer & Sequence & Reference \\
\hline EukA & 5'-AAC CTG GTT GAT CCT GCC AGT-3' & [26], no polylinker \\
EukB & 5'-TGA TCC TTC TGC AGG TTC ACC TAC-3' & \\
$1055 f$ & 5'-GGT GGT GCA TGG CCG TTC TT-3' & [27] \\
$1055 \mathrm{r}$ & 5'-ACG GCC ATG CAC CAC CAC CCA T-3' & \\
\hline
\end{tabular}

\section{Conclusions}

The screening for new thermotolerant microalgal strains for biomass production was successful. Out of 130 environmental samples, 22 freshwater strains were isolated, cultivated and identified on a molecular level. It was found that the maximum temperature tolerated was $40{ }^{\circ} \mathrm{C}$ for eight strains and $45^{\circ} \mathrm{C}$ for 13 strains, respectively. Although the results are promising, further experiments on biomass and secondary metabolite production must be conducted to give a more accurate prediction on the suitability of the isolates for industrial application. Process oriented strain selection is an important factor in making microalgal cultivation economical on an industrial scale. This study identifies new thermotolerant chlorophytes allowing cultivation under high or extreme temperature conditions in greenhouses or outdoor settings.

\section{Supplementary Materials}

Supplementary materials can be accessed at: http://www.mdpi.com/1996-1073/7/12/7847/s1.

\section{Acknowledgments}

We would like to thank Uwe John (Alfred-Wegener-Institute, Bremerhaven, Germany) for his support. Furthermore we would like to thank Angela Rosien, Raeesah Nawaz and Thomas Parry for critical reading of our manuscript. This research was funded by the program FHprofUnt of the Federal Ministry of Education and Research (BMBF) with the grant number 17003X11 and 50WB1265.

\section{Author Contributions}

Franziska Bleeke contributed to experimental design, data acquisition, result analysis and manuscript preparation. Vincent M. Rwehumbiza contributed to result analysis and manuscript preparation. Dominik Winckelmann contributed to experimental design and data acquisition. Gerd Klöck contributed to experimental design, result analysis and manuscript preparation.

\section{Conflicts of Interest}

The authors declare no conflict of interest. 


\section{References}

1. Mata, T.M.; Martins, A.A.; Caetano, N.S. Microalgae for biodiesel production and other applications: A review. Renew. Sustain. Energy Rev. 2010, 14, 217-232.

2. Chisti, Y. Biodiesel from microalgae. Biotechnol. Adv. 2007, 25, 294-306.

3. De Clerck, O.; Guiry, M.D.; Leliaert, F.; Samyn, Y.; Verbruggen, H. Algal taxonomy: A road to nowhere? J. Phycol. 2013, 49, 215-225.

4. Guiry, M.D. How many species of algae are there? J. Phycol. 2012, 48, 1057-1063.

5. Spolaore, P.; Joannis-Cassan, C.; Duran, E.; Isambert, A. Commercial applications of microalgae. J. Biosci. Bioeng. 2006, 101, 87-96.

6. Ras, M.; Steyer, J.P.; Bernard, O. Temperature effect on microalgae: A crucial factor for outdoor production. Rev. Environ. Sci. Bio-Technol. 2013, 12, 153-164.

7. William, K.W.; Morris, I. Temperature adaption in Phaeodactylum tricornutum Bohlin: Photosynthetic rate compensation and capacity. J. Exp. Mar. Biol. Ecol. 1982, 58, 135-150.

8. Hanagata, N.; Takeuchi, T.; Fukuju, Y.; Barnes, D.J.; Karube, I. Tolerance of microalgae to high $\mathrm{CO}_{2}$ and high-temperature. Phytochemistry 1992, 31, 3345-3348.

9. Converti, A.; Casazza, A.A.; Ortiz, E.Y.; Perego, P.; del Borghi, M. Effect of temperature and nitrogen concentration on the growth and lipid content of Nannochloropsis oculata and Chlorella vulgaris for biodiesel production. Chem. Eng. Process. 2009, 48, 1146-1151.

10. Li, X.; Hu, H.Y.; Zhang, Y.P. Growth and lipid accumulation properties of a freshwater microalga Scenedesmus sp. under different cultivation temperature. Bioresour. Technol. 2011, 102, 3098-3102.

11. Butterwick, C.; Heaney, S.I.; Talling, J.F. Diversity in the influence of temperature on the growth rates of freshwater algae, and its ecological relevance. Freshw. Biol. 2005, 50, 291-300.

12. Salvucci, M.E.; Crafts-Brandner, S.J. Relationship between the heat tolerance of photosynthesis and the thermal stability of Rubisco activase in plants from contrasting thermal environments. Plant Physiol. 2004, 134, 1460-1470.

13. Hase, R.; Oikawa, H.; Sasao, C.; Morita, M.; Watanabe, Y. Photosynthetic production of microalgal biomass in a raceway system under greenhouse conditions in Sendai city. J. Biosci. Bioeng. 2000, 89, 157-163.

14. Bechet, Q.; Munoz, R.; Shilton, A.; Guieysse, B. Outdoor cultivation of temperature-tolerant Chlorella sorokiniana in a column photobioreactor under low power-input. Biotechnol. Bioeng. 2013, 110, 118-126.

15. Ong, S.C.; Kao, C.Y.; Chiu, S.Y.; Tsai, M.T.; Lin, C.S. Characterization of the thermal-tolerant mutants of Chlorella sp. with high growth rate and application in outdoor photobioreactor cultivation. Bioresour. Technol. 2010, 101, 2880-2883.

16. Bechet, Q.; Shilton, A.; Fringer, O.B.; Munoz, R.; Guieysse, B. Mechanistic modeling of broth temperature in outdoor photobioreactors. Environ. Sci. Technol. 2010, 44, 2197-2203.

17. Doucha, J.; Livansky, K. Outdoor open thin-layer microalgal photobioreactor: Potential productivity. J. Appl. Phycol. 2009, 21, 111-117.

18. Dalrymple, O.K.; Halfhide, T.; Udom, I.; Gilles, B.; Wolan, J.; Zhang, Q.; Ergas, S. Wastewater use in algae production for generation of renewable resources: A review and preliminary results. Aquat. Biosyst. 2013, 9, 1-11. 
19. Zuppini, A.; Andreoli, C.; Baldan, B. Heat stress: An inducer of programmed cell death in Chlorella saccharophila. Plant Cell Physiol. 2007, 48, 1000-1009.

20. Winckelmann, D.; Bleeke, F.; Bergmann, P.; Klöck, G. Growth of Cyanobacterium aponinum influenced by increasing salt concentrations and temperature. 3 Biotech 2014, doi:10.1007/s13205-014-0224-y.

21. Kessler, E. Upper limits of temperature for growth in Chlorella (Chlorophyceae). Plant Syst. Evol. 1985, 151, 67-71.

22. Cypionka, H. Grundlagen der Mikrobiologie; Springer: Berlin, Germany, 2010.

23. Vaulot, D.; Eikrem, W.; Viprey, M.; Moreau, H. The diversity of small eukaryotic phytoplankton ( $<$ or $=3$ microm) in marine ecosystems. FEMS Microbiol. Rev. 2008, 32, 795-820.

24. Leliaert, F.; Smith, D.R.; Moreau, H.; Herron, M.D.; Verbruggen, H.; Delwiche, C.F.; de Clerck, O. Phylogeny and molecular evolution of the green algae. Crit. Rev. Plant Sci. 2012, 31, 1-46.

25. Keeling, P.J.; Burger, G.; Durnford, D.G.; Lang, B.F.; Lee, R.W.; Pearlman, R.E.; Roger, A.J.; Gray, M.W. The tree of eukaryotes. Trends Ecol. Evol. 2005, 20, 670-676.

26. Medlin, L.; Elwood, H.J.; Stickel, S.; Sogin, M.L. The characterization of enzymatically amplified eukaryotic 16S-like rRNA-coding regions. Gene 1988, 71, 491-499.

27. Elwood, H.J.; Olsen, G.J.; Sogin, M.L. Ther small-subunit ribosomal-RNA gene-sequences from the hypotrichous ciliates Oxytricha-nova and Stylonychia-pustulata. Mol. Biol. Evol. 1985, 2, 399-410.

(C) 2014 by the authors; licensee MDPI, Basel, Switzerland. This article is an open access article distributed under the terms and conditions of the Creative Commons Attribution license (http://creativecommons.org/licenses/by/4.0/). 